\title{
DEVELOPMENT OF A PEDESTRIAN BRIDGE WITH GFRP PROFILES AND FIBRE REINFORCED SELF-COMPACTING CONCRETE DECK
}

Pedro J. D. Mendes ${ }^{1}$, Joaquim A. O. Barros ${ }^{2}$, José M. Sena-Cruz ${ }^{3}$ and Mahsa Taheri ${ }^{4}$

\begin{abstract}
In recent years, the number of pedestrian bridges built from composites materials has notably increased. The combination of fiber reinforced polymers (FRP) profiles with fiber reinforced concrete (FRC) elements is being adopted in this type of structures, since the ductility, high post-cracking tensile strength, compressive stiffness and strength of FRC can be combined with the benefits derived from the use of FRP's profiles to obtain high performance structural systems.

In the context of the present work a $12 \mathrm{~m}$ long single span pedestrian bridge with two composite Iprofiles was designed. In terms of deflection requirements imposed by serviceability limit states, the influence of the height and thickness of GFRP (Glass Fiber Reinforced Polymer) profiles, as well as the addition of a thin layer of prestressed carbon fiber sheet in the bottom flange of the GFRP profile was evaluated. Using software based on the finite element method, the structural behavior of the developed structural systems was analyzed. Furthermore, two prototypes of this structural system were built and monitored in order to assess their long-term deformational behavior when subjected to a loading configuration correspondent to the load combination for the deflection serviceability limit states. The main results obtained are presented and discussed.
\end{abstract}

KEYWORDS: Pedestrian bridge; Composites; GFRP pultruded profiles; Fiber Reinforced self-compacting concrete; Creep; Finite element method

\section{Introduction}

In the last decades, the materials used in construction of pedestrian bridges were essentially steel, wood and reinforced concrete. The susceptibility of these materials to ageing-damage environmental agents has, in general, a significant impact in the life-cycle costs of a structure, due to its maintenance and rehabilitation. In addition, the need for fastest construction has having a booster effect on the development and use of new structural materials and systems, lighter, with less concerns about maintenance and less exposed to degradation caused by environment agents (Correia 2008). These new structural materials, also named by composite materials, were first used in the mid 1950s to reinforce concrete structures (Rubinsky \& Rubinsky, 1954; Wines et al., 1966 cit in ACI Committee 440, 1996).

A significant part of the composites that are used by modern society is the Plastics Reinforced with various types of fibers, also named by FRP (Fiber Reinforced Polymer). The application field of FRP until recently was restricted to aerospace and shipbuilding industries, due to the high performance

\footnotetext{
${ }^{1}$ Researcher, ISISE, Dept. of Civil Engineering, Univ. of Minho, Campus de Azurém, 4810-058 Guimarães, Portugal. E-mail: pedromendes27@me.com

${ }^{2}$ Associate Professor, ISISE, Dept. of Civil Engineering, Univ. of Minho, Campus de Azurém, 4810-058 Guimarães, Portugal. E-mail: barros@civil.uminho.pt; Corresponding author

${ }^{3}$ Assistant Professor, Dept. of Civil Engineering, Univ. of Minho, Campus de Azurém, 4810-058 Guimarães, Portugal. E-mail: jsena@ civil.uminho.pt

${ }^{4}$ Researcher, ISISE, Dept. of Civil Engineering, Univ. of Minho, Campus de Azurém, 4810-058 Guimarães, Portugal. E-mail: taheri.mahsa09@gmail.com
} 
requirements they demand to the materials. Furthermore, these materials were too expensive to compete in construction industry (Bakis et al., 2002). However, in the last few years, the demands of the construction industry, the advances in the research in the composites field, in addition to the decrease of FRP production costs (Bakis et al., 2002), allowed the use of these materials in the construction industry (Correia, 2008). These structural materials have been used in a significant number of structures to-date, such as pedestrian bridges, road bridges, building frames, stair towers, cooling towers and walkways (Chen \& Lui, 2004). Due to the many advantages they offer, FRP structural elements are used in several ways in the construction of bridges. According to Keller (2003), FRP systems are frequently used for repair work and for new bridges as: reinforcing bars for concrete; strips and sheets for structural strengthening; beams and trusses; and, bridge deck slabs. Some major examples can be found in Europe: 114m long cable-stayed Aberfeldy Pedestrian Bridge in Aberfeldy, Scotland (Bakis et al., 2002); 40m long cable-stayed Fiberline Bridge in Kolding, Denmark (Bakis et al., 2002); 38m span Lleida Pedestrian Bridge, Spain (Correia, 2008).

Another important innovation in bridges construction is the use of self-compacting concrete (SCC), which is a concrete that does not require vibration for placing and compaction. The SCC is highly flowable, without the loss of stability, and is able to flow under its own weight completely filling formwork and achieving full compaction, even in the presence of congested reinforcement (EFCA, 2005). The first steps in the development of this flowable material were given by researchers at the University of Tokyo, Japan, in late 1980's (Okamura \& Ouchi, 1999), recognizing the lack of uniformity and complete compaction of concrete by vibration when the percentage of reinforcement is relatively high. However, the first known application of SCC was in early 1990's in a prototype assembled in Japan. Ever since, European countries were interested in developing the potentialities of SCC. Hence, a number of SCC bridges, walls and tunnels have been made in Europe (Ouchi et al., 2003). In the United States, the SCC application in bridge construction has been very limited (Ouchi et al., 2003).

More recently, researchers are developing Fiber Reinforced Self-Compacting Concrete, FRSCC, which consists in the addition of fibers (typically, steel fibers or synthetic fibers) to the SCC composition. The advantage of this mixture is the possibility of obtaining a new material combining the excellent properties of SCC and fibers (Barros et al., 2007). The addition of steel fibers to a cement based composition can increase significantly its post-cracking residual strength, but the fluidity and the workability have a general tendency to decrease. To avoid segregation of FRSCC constituents suitable mix design methodologies should be adopted (Pereira 2006).

To appraise the efficiency of combining FRSCC and GFRP materials in the construction of a pedestrian bridge, numerical simulations and an experimental program were carried out. The pedestrian bridge analyzed is composed by two pultruded GFRP (Glass Fiber Reinforced Polymer) I shape profiles disposed longitudinally, and connected to a Steel Fiber Reinforced Self-Compacting Concrete (SFRSCC) deck (see Fig. 1). The SFRSCC deck is intended to withstand the compressive stresses, and the GFRP profiles will handle the tensile stresses. Steel anchors and an epoxy resin make the connection between both materials. The SFRSCC layer has also the role of increasing the flexural stiffness of this structural concept.

Due to the very small thickness of the concrete layer $(40 \mathrm{~mm})$, the deck is quite susceptible to the occurrence of macro-cracks during its curing, handling and assembling processes. Furthermore, if prestress or pos-tension strategies are adopted to overcome deflection requirements imposed by code-design 
recommendations, strains higher than cracking strain can occur in this concrete layer. Therefore, to avoid unacceptable crack patterns and crack widths, a SFRSCC material of relatively high post-cracking residual strength is used for the deck.

\section{Material properties}

Table 1 shows the mixture composition of the developed SFRSCC, and Table 2 presents its mechanical and rheological properties. Forty five $\mathrm{kg} / \mathrm{m}^{3}$ of hooked ends steel fibers of $35 \mathrm{~mm}$ length, 0.55 $\mathrm{mm}$ diameter and $1100 \mathrm{MPa}$ tensile strength were used. The methodology followed to formulate the SFRSCC composition is mainly based on the following three steps (Pereira 2006): i) the proportions of the constituent materials of the binder paste are defined; ii) the proportions of each aggregate on the final granular skeleton are determined; iii) binder paste and granular skeleton are mixed in distinct proportions until self-compacting requirements in terms of spread ability, correct flow velocity, filling ability, blockage and segregation resistance are assured, allowing the determination of the optimum paste content in concrete.

The GFRP profiles were produced by the pultrusion process and are composed by E-glass fibers embedded in a polyester matrix. In accordance with several tests performed with this type of material (Correia, 2004), the average tensile strength in the direction parallel to the fibers is $500 \mathrm{MPa}$ and the compressive strength in the same direction is $375 \mathrm{MPa}$. Moreover in the context of this work, two GFRP profiles were tested to evaluate the Young's modulus, and the value of $34 \mathrm{GPa}$ was obtained.

\section{Creep tests}

\subsection{Creep}

Creep in the present context, is the tendency of a hardened material to deform under permanent load. This phenomenon occurs as a result of long-term exposure of the material to relatively high stress levels. Creep is more severe in materials that are subjected to high temperatures for long periods. The increase rate of the creep with temperature is a function of the exposure time, exposure temperature, material properties and loading conditions (Monteiro, 2005). Moderate creep can be favorable if it relieves tensile stresses that might otherwise lead to cracking. The creep time-dependent deformation can, however, constitute a failure mechanism.

\subsection{Pedestrian bridge prototypes}

To understand the behavior of the present pedestrian bridge structural system, regarding to the longterm deflection, two prototypes were developed.

The geometry of these prototypes was inspired from the structural system of the pedestrian bridge. However, the prototype length, $6 \mathrm{~m}$, is only half of the original bridge span and the transverse dimension of the SFRSCC deck $(0.5 \mathrm{~m})$ is four times smaller than the original bridge. The dimensions of both prototypes involved in the creep tests are equal. Fig. 2 and Fig. 3 show the dimensions of the prototypes, as well as the support conditions. The motivation to develop two prototypes was to evaluate the influence of two different connection configurations between the SFRSCC deck and the GFRP profiles. The connection between the GFRP profiles and the SFRSCC deck is made by M10 steel anchors, glued to the 
concrete deck by HIT-HY 150 MAX epoxy resin, bolted to the GFRP profiles. The surfaces of the concrete deck and the GFRP profiles in contact are also glued by the epoxy adhesive S\&P ${ }^{\circledR}$ Resin 220 . The anchors are inserted $30 \mathrm{~mm}$ into the concrete deck to allow enough contacting area between the anchors and the concrete. The difference between the two prototypes is restricted to the longitudinal distance between the M10 anchors, which is $125 \mathrm{~mm}$ in one prototype (PROT_125), and $200 \mathrm{~mm}$ in the other (PROT_200). Fig. 4 shows the connection configuration, and Fig. 5 shows the steps followed to assemble the connection. Regarding to the load configuration, the Eurocode 1, part 2 (CEN/CENELEC, 2003) recommends that for the design of pedestrian bridges a uniformly distributed load $q_{f k}$, calculated according to the equation (1), should be applied only in the unfavorable parts of the influence surface, longitudinally and transversally.

$$
q_{f k}=2,0+\frac{120}{L+30}\left[\mathrm{kN} / \mathrm{m}^{2}\right] \quad ; \quad q_{f k} \geq 2,5 \quad\left[\mathrm{kN} / \mathrm{m}^{2}\right] \quad ; \quad q_{f k} \leq 5,0 \quad\left[\mathrm{kN} / \mathrm{m}^{2}\right]
$$

where $L$ is the loaded length in meters. Therefore, from the equation (1), and for a loaded length of $5.7 \mathrm{~m}$, results a uniformly distributed load of $5 \mathrm{kN} / \mathrm{m}^{2}$ applied across the deck surface. To estimate the long-term effects, the Eurocode 0 recommends the quasi-permanent load combination, where $30 \%$ of the live load is adopted. However, these recommendations are suitable for reinforced concrete structures and there is no standard for this type of structures. Hence, the live load used in the creep tests was adjusted to allow a faster evaluation of the creep effect i.e., to appraise the creep in the short time available for this project, so $4 \mathrm{kN} / \mathrm{m}^{2}$ was considered for the live load. This uniformly distributed load was materialized by applying cement bags of $40 \mathrm{~kg}$ (see Fig. 6). To measure the mid-span deflection, the strains in the SFRSCC deck and in the GFRP profile, dial gauges were used and positioned at mid-span alignment in four different places in each prototype (see Fig. 7). One dial gauge (DI_A, $5 \mathrm{~mm}$ stroke and $1 \mu \mathrm{m}$ accuracy) was fixed on the deck lateral face (at mid height) and was used to measure the concrete strain. The DI_B (5 mm stroke and $1 \mu \mathrm{m}$ accuracy) was fixed on the top flange of the GFRP profile (centered in the half flange) to measure the strains at this point. To evaluate the strain in the bottom flange of the GFRP profile, the DI_C (10 mm stroke and $10 \mu \mathrm{m}$ accuracy) was used (positioned at mid-flange). The dial gauge DI_D (40 $\mathrm{mm}$ stroke and $10 \mu \mathrm{m}$ accuracy) measured the mid-span deflection. Note that due to the relative large size of the prototypes, it was not possible to use a climatic chamber to control the exposure temperature and humidity.

\subsection{Results}

\subsubsection{Long-term deflection}

The creep tests were carried out between August $10^{\text {th }}$ and September $29^{\text {th }}$ of 2010 , with duration of 51 days. When the live load was applied the concrete age was 90 days. During this period the climate was hot (approx.: $32{ }^{\circ} \mathrm{C}$ ) and dry (approx.: $22 \%$ ), especially in the first 20 days. On the other hand, in the last 23 days of the live loading period was registered a decrease in the temperature, and an increase in the humidity. The difficulty of assuming perfect symmetric loading conditions may have caused the fell of the PROT_200 from its supports at 21 days of the loading process. Therefore, the PROT_200 values were measured during 21 days, and the PROT_125 values were measured during 51 days. Fig. 8 shows the time-deflection relationship of both prototypes along with the measured temperature.

The evolution of the deflection was similar in both prototypes up to $21^{\text {st }}$ day. At this day the deflection of PROT_125 and PROT_200 was $16.5 \mathrm{~mm}$ and $17.1 \mathrm{~mm}$, respectively. The deflection of PROT_125 at 
$51^{\text {st }}$ day was $18.0 \mathrm{~mm}$. To evaluate the creep influence in the long-term deflection of both prototypes, the short-term deflection was measured (elastic deflection), which was considered as the deflection occurred just after the last cement bag has been applied. The instantaneous deflection of PROT_125 and PROT_200 was $11.9 \mathrm{~mm}$ and $11.5 \mathrm{~mm}$, respectively, which is in agreement with the instantaneous elastic deflection predicted by Bernoulli theory of beams $(11.6 \mathrm{~mm})$.

Fig. 9 represents the relationship between the $\mu(t) / \mu(0)$ ratio and time (in days) for both tested prototypes, where $\mu(0)$ and $\mu(t)$ are the instantaneous deflection and the deflection at $t$ days after the live load has been applied, respectively. According to this figure, it is noticeable that similar results were obtained for both prototypes, in terms of creep deflection. The deflection in the PROT_125 has increased $51 \%$, after 51 days, and $48 \%$ in the PROT_200 after 21 days, due to creep effect. At 21 days of exposure, the deflection of PROT_125 has increased $38 \%$, hence the difference between both at 21 days of exposure is $10 \%$, which means that, with the anchors spaced by $200 \mathrm{~mm}$, the creep deflection tends to be $10 \%$ higher than when spaced by $125 \mathrm{~mm}$.

Fig. 10 represents the time variation of the relative flexural stiffness $(E I(t) /(E I(0))$ registered in both prototypes, where $E I(0)$ and $E I(t)$ is the instantaneous elastic flexural stiffness and the flexural stiffness at $t$ days after live load application, respectively. The flexural stiffness was estimated based on the theory of elasticity, according to the load and the deflection obtained.

Due to creep effect, at the end of 21 and 51 days the relative flexural stiffness has decreased $35 \%$ and $46 \%$, respectively. In Fig. 10 it is also represented the Equation:

$$
\frac{E I(t)}{E I(0)}=\frac{1+t^{1.11}}{1+1.35 \cdot t^{1.185}}
$$

that best fits the experimental data up to 51 days. According to this equation, the $E I(t) / E I(0)$ at 50 and 100 years will be $826.1 \mathrm{kN}^{\cdot} \mathrm{m}^{2}$ and $778.9 \mathrm{kN}^{\cdot} \mathrm{m}^{2}$, which corresponds to a flexural stiffness that is $35 \%$ and $33 \%$ of the corresponding instantaneous elastic flexural stiffness.

To estimate the long-term deflection due to creep, the creep behavior of the SFRSCC layer was estimated according to the recommendations of Eurocode 2, part 1 (CT 115, 2004) and CEB-FIP Model Code 1990 (CEB, 1993), and the creep behavior of the GFRP was determined adopting the creep law suggested by Bank (Bank, 2006).

Therefore, and regarding to the concrete creep law, to appraise the effective concrete modulus during the time, the Equation (3) was used, where the creep parameter, $\varphi\left(t, t_{0}\right)$, was calculated using equation (4).

$$
\begin{gathered}
E_{c, \text { eff }}=\frac{E_{c m}}{1+\varphi\left(t, t_{0}\right)} \\
\varphi\left(t, t_{0}\right)=\varphi_{0} \cdot \beta_{c}\left(t-t_{0}\right) \\
\beta_{c}\left(t-t_{0}\right)=\left[\frac{\left(t-t_{0}\right) / t_{1}}{\beta_{H}+\left(t-t_{0}\right) / t_{1}}\right]^{0.3}
\end{gathered}
$$

where $E_{e, e f f}$ is the effective modulus of elasticity of concrete; $E_{c m}$ is the concrete secant modulus of elasticity at 28 days; $\varphi_{0}$ is the is the notional creep coefficient; $\beta_{c}\left(t-t_{0}\right)$ is the coefficient to describe the development of creep with time after loading, where $t$ is the time in days, and $t_{0}$ is the age of the concrete at time of loading, in days.

Regarding to the GFRP profiles, and according to Bank's theory for creep (Bank, 2006), the GFRP longitudinal viscoelastic modulus, $E_{L}^{v}$, should be calculated using the following equation: 


$$
E_{L}^{v}=\frac{E_{L}}{1+\left(\frac{E_{L}}{E_{L}^{t}}\right) \cdot t^{n_{e}}}
$$

where $E_{L}$ is the instantaneous modulus $(34 \mathrm{GPa}) ; E_{L}^{t}$ is the creep moduli $(1.23 \mathrm{GPa}) ; t$ is the time in hours after loading and $n_{e}$ is the creep rate exponent (0.3).

Using equations (3) to (6), the concrete and the GFRP modulus were calculated for the ages coinciding with records in terms of temperature and humidity, in order to take this information into account in the evaluation of $\beta_{c}\left(t-t_{0}\right)$, as suggested by CEB-FIP 1990. Knowing $E_{c, e f f}$ and $E_{L}^{v}$ for the SFRSCC and GFRP profile, respectively, the time-deflection evolution was determined and compared to the values registered experimentally, in Fig. 9. It is noticeable that for the first 15 days, the results are very similar, and for the $51^{\text {st }}$ day the difference between the analytical prediction and the experimental results is only $6 \%$ (approximately $1 \mathrm{~mm}$ ). These results demonstrate that the creep behavior of the bridge prototypes can be reasonably predicted with available analytical models. Therefore, applying this analytical approach to appraise the creep deflection for 50 and 100 years, an increase of $158 \%$ and $186 \%$ is obtained when compared to the instantaneous deflection, respectively (see Fig. 9).

\subsubsection{Creep strains and stresses}

As previously referred, the dial gauges used to measure the strains were positioned at the concrete deck, GFRP profile top flange and GFRP profile bottom flange (see Fig. 7). Fig. 11 shows the time-strain relationship for these three analyzed positions and for both tested prototypes. In these figures it is visible that the middle surface of the SFRSCC deck is under compressive strain, while the top and the bottom flange of the GFRP profile are under tensile strains. Table 3 shows the measured values for both prototypes at 21 days and, in the case of the PROT_125, also at 51 days. In the first 21 days the results were similar in both prototypes and the differences can be caused by several factors, such as small differences in the loading conditions, the supports/position of the dial gauges, the assemblage of the constituent elements of the prototypes and their materials properties. Therefore, the influence of the longitudinal distance between the M10 anchors on the flexural behavior at the end of 21 days of loading seems to be not significant. This means that using a small distance between the M10 anchors does not bring any significant benefit in terms of creep deflection for service limit states (SLS). Fig. 12 and Fig. 13 show the creep influence in the strain diagrams at 21 and 51 days, respectively. The darkest part of the diagram corresponds to the instantaneous strains, while the clearest part corresponds to the long-term strains. The increase percentage of strain that was caused by creep is also indicated in these figures. Note that the compressive strain diagram was represented by a dotted line because there is no certainty if some sliding between SFRSCC deck and the top flange of the GFRP profile has occurred.

In general, similar results were obtained in both prototypes at the end of 21 days of loading (see Fig. 11), demonstrating once again that the distance between the M10 anchors has no influence in the flexural behavior for SLS. At the end of 51 days of loading, the strains in PROT_125 have increased more significantly, being the SFRSCC deck the point where the highest increment was measured (150\%). The tensile strain in the bottom flange of the GFRP profile has increased $75 \%$, while in the top flange the strain has increased $60 \%$. Using the models based on Equations (3) to (6), the strains can be estimated at 50 and 100 years. The obtained values are indicated in Table 3. The increase in the compressive strain in the SFRSCC layer at the end of 50 and 100 years is $253 \%$ and $258 \%$, respectively. For the tensile strain 
in the bottom flange, the increase at the end of 50 and 100 years is $163 \%$ and $195 \%$, respectively. However, as seen in Table 3, using the previous law's in a FEM based model to predict the long-term strains, the neutral axis position differs from the one obtained in the creep tests. Nonetheless, some slight differences were registered when comparing the values obtained numerically up to the 51th day, which can be justified by the laws' used, i.e., the creep law used to estimate the effective concrete modulus is suitable for ordinary concretes, and regarding to the creep law for the GFRP profiles, the Bank theory was based in pultruded profiles with $40 \%$ of fiber reinforcement, which differ from the ones used in the present paper (62\% according to Correia, 2004), hence, this can result in slightly differences. Concluding, these results show that the creep influence, in the long-term strains, is an important factor to the bridge design.

Moreover, from the previous models (Equations (3) to (6)) and performing FEM analysis, the evolution of the stresses can be estimated at 50 and 100 years. Table 4 shows the instantaneous stresses for both prototypes, and the predicted stresses at the end of 50 and 100 years. These results show that, if instantaneous values are considered for comparison purposes, the stress increment at the end 50 and 100 years is $-1.3 \%$ and $0.4 \%$ for concrete. For the bottom flange of the GFRP profile, and assuming the analytical position of the neutral axis, the increment in the tensile stress is $0.9 \%$ and $0.2 \%$ for 50 and 100 years.

At 50 and 100 years the stress levels in the SFRSCC deck and GFRP profiles are similar to the corresponding instantaneous ones, and quite inferior to the stress limits recommended for these materials.

\section{Numerical analysis}

\subsection{Load cases, combinations and design bending moments}

The cross-section geometry of the $12 \mathrm{~m}$ long and $2 \mathrm{~m}$ wide pedestrian bridge can be seen in Fig. 1. For the live load the Eurocode 1, part 2 (CEN/CENELEC, 2003) recommends a value of $5 \mathrm{kN} / \mathrm{m}^{2}$ (see section 3.1). For the permanent load, the deadweight of the SFRSCC deck and GFRP profiles are considered. Thus, the SFRSCC deck with a thickness of $0.04 \mathrm{~m}$ leads to a uniformly distributed load of 1 $\mathrm{kN} / \mathrm{m}^{2}$. Regarding to the GFRP profiles, and based on a pre-design study, where the geometry of the GFRP profile was obtained from its inertial momentum, and using a design criteria in terms of deflection limit, a $300 \mathrm{~mm} \times 700 \mathrm{~mm} \times 15 \mathrm{~mm}$ GFRP profile with a mass of $32.0 \mathrm{~kg} / \mathrm{m}$ was determined, resulting in a uniformly distributed load of about $0.32 \mathrm{kN} / \mathrm{m}^{2}$. Hence, for the deflection at serviceability limit states, the characteristic load combination was used, leading to a load of $(1.0+0.32)+5.0=6.32 \mathrm{kN} / \mathrm{m}^{2}$, and to appraise the long-term deflection the quasi-permanent combination was used resulting in a load of $(1.0+0.32)+0.3 \times 5.0=2.82 \mathrm{kN} / \mathrm{m}^{2}$. For the ultimate limit states, the fundamental load combination was adopted, leading to a load of $1.35 \times(1.0+0.32)+1.5 \times 5.0=9.28 \mathrm{kN} / \mathrm{m}^{2}$. The design bending moment at mid span for the serviceability limit state is $113.76 \mathrm{kN}^{\cdot} \mathrm{m}$, for the long-term deflection is $50.8 \mathrm{kN} \cdot \mathrm{m}$ and for the ultimate limit states is $167.04 \mathrm{kN} \cdot \mathrm{m}$.

\subsection{Parametric study using a cross-section layer model}

In the first stage, the moment-curvature relationship of the deck connected to GFRP profiles crosssection was estimated for distinct arrangements of the GFRP I-profile cross-section, i.e., a parametric study was carried out in order to determine the most effective arrangements (Table 6). For this analysis the DOCROS software (Design Of CROss Sections) was used (Basto and Barros 2008), which is capable 
of predicting the flexural capacity of these specimens by using a cross section layer model. This model assumes that a plane section remains plane after deformation and bond between materials is perfect. The section is divided in horizontal layers, and the thickness and width of each layer is user-defined and depend on the cross-section geometry. DOCROS can analyze sections of irregular shape and size, composed of different material type, submitted to an axial force and variable curvature. Composite layers are used when more than one material exist at same depth of the cross section. Each layer can have an initial non-null stress in order to simulate a pre-stress effect. The software can also analyze sections that have layers with distinct construction phases, such is the case of retrofitting, where strengthening materials are active in later phases. DOCROS has a wide database of constitutive laws for the simulation of monotonic and cyclic behavior of cement based materials, polymer based materials and steel bars.

The basis of this parametric study consists in the variation of the thickness of the GFRP flanges and web components, along with the width and depth of the I-profile. The deck thickness remained constant and equal to $40 \mathrm{~mm}$. The SFRSCC properties used in numerical analysis are shown in Table 5 and Fig. 14 (note that negative means compression). The indicated values were determined from experimental tests (Häßler 2010) and the tensile strain-softening diagram was obtained from inverse analysis, which algorithm is described elsewhere (Cunha, 2010).

Once assessed the moment-curvature relationship, the mid-span deflection was obtained by taking the initial flexural stiffness $(\mathrm{EI})_{0}$, and substituting this value in the equation based on the theory of elasticity to predict the deflection of simple supported beams. The GFRP profile was assumed as having a linearelastic behavior characterized by an elasticity modulus of $34 \mathrm{GPa}$, in agreement with the test results and data provided by the supplier.

\subsubsection{Results}

The deflection limit of $L / 250$, where $L$ is the total loaded length, recommended by Eurocode 2, part 11 (CT 115, 2004) was assumed to determine the most appropriate GFRP profile. Therefore, for a loaded length of $12 \mathrm{~m}$, the instantaneous deflection limit is $48.0 \mathrm{~mm}$. However, as the creep tests shows, the creep deflection is quite relevant, and should be taken into account in the design. Therefore, and for a working life of 100 years, as suggested by Eurocode 0 (CEN/TC 250, 2002) for the design of bridges, the instantaneous deflection obtained with the quasi-permanent load combination should be multiplied by 2.85 (which is the value obtained analytically for 100 years) (see Fig. 9).

The moment-curvature relationship depicted in Fig. 15 shows two important factors: the first one is the almost linear behavior of the bridge up to peak load; the second one is that the failure is governed by the maximum allowable tensile stress that can be applied in the GFRP profile (500 MPa). Thus, this failure occurs when the maximum allowed strain is reached, causing a reduction in the resistant bending moment of the cross-section. Regarding to the deflection serviceability limit state condition, the crosssections 1.1, 1.3 and 1.5 are the only ones that verify this limitation $(34.94 \mathrm{~mm}, 35.36 \mathrm{~mm}$ and $34.44 \mathrm{~mm}$, respectively, Table 6). Furthermore, the long-term deflection for 100 years is accomplished in all the cross sections.

\subsection{FEM-based analysis}

The behavior of the pedestrian bridge was simulated using the FEMIX 4.0, a computer program that is based on the Finite Element Method (Sena-Cruz et al., 2007) and includes several types of finite 
elements and constitutive models for the linear and material nonlinear analysis of cement-based and polymer-based composite materials. The GFRP profiles were modeled using 8-node Mindlin shell elements with $2 \times 2$ Gauss-Legendre integration scheme, and the SFRSCC bridge deck was modeled using 20-node solid elements with $2 \times 2 \times 2$ Gauss-Legendre integration scheme. A perfect bond between both materials was assumed. In the following section the influence of other types of bond conditions on the behavior of this pedestrian bridge is analyzed.

The supports of the pedestrian bridge will be positioned $0.25 \mathrm{~m}$ from the bridge end, therefore the bridge span is $11.5 \mathrm{~m}$ (Fig. 16). The displacement in X3 direction of all the nodes represented in black markers in Fig. 16 was restricted. In addition, the displacements in X1 and X2 directions of one node were also restricted, in order to prevent the movement of the bridge in these directions.

The concrete properties used in the pedestrian bridge simulation are equal to the ones used in the parametric study i.e., the SFRSCC is characterized by a Young's modulus of $32 \mathrm{GPa}$ and a Poison's ratio of 0.15. Moreover the SFRSCC was simulated assuming a linear and elastic behavior, since the results of the parametric study showed that the stress levels are low and the deck is only under compression. The GFRP profiles were simulated assuming they have a linear elastic behavior.

\subsubsection{Results}

In a first stage the cross-sections 1.1 and 1.5 of the parametric study (Table 6) were simulated, since this study shown that with these GFRP profiles the deflection limit condition imposed by Eurocode 2, part 1-1 (CT 115, 2004) is accomplished. The obtained results from FEM-analysis were similar to the ones obtained with the cross-section layer model.

In a second stage, the benefits of adding a carbon fiber reinforced polymer (CFRP) sheet to the bottom flange of the GFRP profile were explored (see Fig. 17). The CFRP sheets are characterized by a Young's modulus of $220 \mathrm{GPa}$, a Poisson coefficient of 0.18 , and a tensile strength of $2500 \mathrm{MPa}$.

In a first approach, the influence of adding a thin CFRP layer of $0.15 \mathrm{~mm}$ to the previous studied cross-sections (Sec. 1.1 and 1.5) was assessed. The results showed that adding this CFRP sheet the deflection of the structure having the cross-sections 1.1 and 1.5 has decreased $2.8 \%$ and $3 \%$ respectively, which was not a significant improvement in terms of deformational behavior. Thus, in order to obtain a higher decrease in the deflection, thicker layers of CFRP were considered. Therefore, for the second approach, an all-new set of cross-sections was modeled, with a thinner thickness for GFRP web and flanges, when compared to the previous studies. Table 7 shows the geometry assumed for each crosssection. The results included in Table 8 , for the serviceability limit states, show that the bridge deck is only subjected to compressive stresses, since the neutral axis of the cross-section is located at the GFRP profile web. The average compressive stress in the SFRSCC reaches only $26 \%$ of the compressive stress limitation $\left(0.45 f_{c k}\right)$. In the GFRP profile, the maximum tensile stress (bottom flange) and the maximum compressive stress (top flange) reach, on average, $8 \%$ and $1.2 \%$ of the corresponding ultimate capacity. The relatively high elasticity modulus of the CFRP sheet, when compared to the one of the GFRP profiles, results in a predominantly stress concentration in the CFRP sheet, however, on average, only $10 \%$ of the ultimate CFRP tensile strength was mobilized. The instantaneous deflection condition for serviceability limit state condition was accomplished in all the cross-sections, along with the long-term deflection for a working life of 100 years (see section 4.2.1). Therefore, a relatively low percentage of CFRP sheets can contribute significantly to decrease the deflection of this structural system. However, 
the costs of adopting CFRP need to be taken into account. Adopting this hybrid reinforcement concept, the cross-section of the GFRP profile can be limited to 500x200x10 $\mathrm{mm}^{3}$, while in the previous studies the deflection serviceability limit state condition was achieved with a 550x200x15 mm $\mathrm{mm}^{3}$ GFRP profile. The results of the analyzed cross-sections for the fundamental load case combination correspondent to the ultimate limit states are presented in Table 9, showing an increase in the stresses of $47 \%$, when compared to the serviceability limit states, among all the cross-sections in all analyzed points. However, none of the analyzed cross-sections exceeds the stress limits imposed by design standards.

Lastly, in a third stage, to reduce the GFRP profile's cross-section, without compromising the deflection for the SLS, the effect of applying prestressed CFRP sheets in the bottom flange of the GFRP profile was assessed. The prestress applied in the CFRP sheet was equivalent to $40 \%$ of the CFRP ultimate tensile stress (1000 MPa). To simulate the prestress applied in the CFRP sheet, a uniform thermal loading was used.

The adoption of this structural solution allowed the use of smaller GFRP profiles, resulting benefits from the economical and esthetical point of views. Therefore, five different cross-sections were modeled, each one with different thicknesses of web, flange and CFRP sheets, maintaining the profile width and height constant (see Table 10).

The results for the serviceability limit states (see Table 11) reveal that for the pre-stress level applied to the CFRP, the SFRSCC deck is still subjected to compressive stresses, reaching, on average, only $30 \%$ of the compressive stress limitation, which is $4 \%$ higher than the previous case. Moreover, the upward deflection imposed by the application of prestress in the CFRP sheets, results in tensile stresses in the SFRSCC layer, however only $67 \%$ of the tensile strength is reached (1.2 MPa). The GFRP profiles become submitted to lower stress levels, when compared to the previous cases, reaching on average, $6.4 \%$ of the ultimate tensile stress and $1.3 \%$ of the ultimate compressive stress. The CFRP sheets are subjected to higher stresses, reaching, on average, $57 \%$ of the CFRP ultimate tensile stress, which means that after the application of $40 \%$ of the CFRP ultimate tensile stress in the CFRP layer, the applied load leads to an increase of $17 \%$ in the CFRP tensile stress (Table 11). The instantaneous deflection for serviceability limit state condition was accomplished in all the cross-sections analyzed, along with the long-term deflection for a working life of 100 years. The results of the analyzed cross-sections for the fundamental load case combination correspondent to the ultimate limit states are presented in Table 12.

Using this structural solution all the pre-established design criteria are accomplished with a 450x200x $8 \mathrm{~mm}^{3}$ GFRP profile with a pre-stressed CFRP sheet of $0.40 \mathrm{~mm}$, while the use of a non prestressed CFRP sheet required a 500x200x10 $\mathrm{mm}^{3}$ GFRP profile with a CFRP sheet of $0.8 \mathrm{~mm}$ thickness.

To assess the influence of the bond conditions between SFRSCC deck and GFRP profiles in terms of deflection and stress levels for serviceability limit states, the cross section 2.5 (Table 7) was analyzed by FEMIX computer program assuming two distinct approaches: 1) perfect bond (the results are those indicated in Table 6); 2) assuming the possibility of occurring debond, by simulating the M10 anchors (8.8 steel class) by Timoshenko 3D elements and 3D interface finite elements to model the two sliding and the opening modes for the connection between the $\mathrm{S} \& \mathrm{P}^{\circledR}$ Resin 220 and the other materials (GFRP profile and SFRSCC deck). The influence of the sliding and normal stiffness of the adhesive was analyzed by considering a wide range of values for the corresponding modes of the interface finite elements (Mendes 2010). The obtained results showed that assuming a perfect bond between SFRSCC deck and GFRP profiles is quite correct since the maximum difference of mid-span deflection and stress levels between the 
two aforementioned approaches is smaller than $2 \%$. The relative reduced impact on the results when changing the values of the stiffness components of the adhesive is justified by the almost equal values of the SFRSCC and GFRP profile Young's modulus. The analyzes that were carried out also showed that, at serviceability limit states, the influence of steel connectors for the deflection and stress levels is marginal, so the connection seems to be made exclusively by the $S \& P \AA$ Resin 220 . Nonetheless, as shown by Neto \& Lebr, 2010, that used a similar structural concept, the use of connectors can increase only to some extent the ultimate failure load. However, research should be carried out in order to appraise the bond conditions between these materials at long-term and when subjected to real weathering conditions, and fatigue load conditions should also be investigated in this context.

\subsection{Final proposal}

To choose the final proposal, an evaluation of the material and implementation costs was made. Therefore, from the prices provided by the suppliers of the GFRP profiles and FRP sheets (see Table 13), a cost analysis was made. Taking into account the previews numerical analysis, three main structural systems were studied: 1) the first considering the GFRP profile; 2) the second considering a CFRP sheet bonded to the bottom flange of the GFRP profile; 3) the third one considering a pre-stressed CFRP sheet bonded to the bottom flange of the GFRP profile. In these analyses the SFRSCC deck maintained their geometric and material properties Therefore, only the girder configuration has changed, hence the cost analysis was centered on the cost's optimization of this structural element. Fig. 18 presents the girder's costs of the three structural systems used, optimized according to the provided prices. Note that the profile's cross-section was chosen in order to get the lowest cross-sectional area, and the web/flange thickness no thinner than $8 \mathrm{~mm}$, to avoid shear failure.

The results show that the third girder configuration is the cheapest $(7996,8 €)$, being $50 \%$ and $30 \%$ cheaper than the first and the second girder configuration, respectively. Moreover, to take advantage of the lower price of GFRP sheets, these were used in the Sec. 3.2 to replace the CFRP pre-stressed sheets (Sec. 3.2A, see Fig. 18). However, using GFRP pre-stressed sheets a thicker layer is required $(1.2 \mathrm{~mm})$ to verify the deflection for the SLS, resulting in a more expensive solution (8400€). Therefore, and according to the provided prices, the final proposal is a $450 \times 200 \times 8 \mathrm{~mm}^{3}$ GFRP profile with a $0.4 \mathrm{~mm}$ CFRP prestressed sheet bonded to the GFRP profile bottom flange (Sec. 3.2, see Fig. 18).

Additionally, analyzing the shear stresses at the profile's web, it was noticeable a higher concentration near the supports area, though, the shear strength was not reached (33 MPa, according to Correia, 2004). Nonetheless, and in agreement with Neto \& Lebr (2010), to prevent shear buckling effects near the supports, the profile's web was reinforced with GFRP U configuration profiles in these zones (see Fig. 19).

Finally, and according to Yu Bai \& Keller (2008), the lightweight nature of FRP structures also raises concerns with respect to their dynamic response. This phenomenon can lead to excessive structural vibrations and may substantially increase the dynamic amplification of stresses and deflections. Furthermore, the study carried out by Yu Bai \& Keller (2008) showed that the joint type used (bolted or bonded) has relevant influence on the dynamic behavior of lightweight FRP-based pedestrian bridges. Therefore, an experimental program for the evaluation of the dynamic response of the developed pedestrian bridge prototypes is in course. 


\section{Conclusions}

In this work a composite solution for a pedestrian bridge of $12 \mathrm{~m}$ span is proposed, composed by a deck made by steel fiber reinforced self-compacted concrete (SFRSCC) of $40 \mathrm{~mm}$ thickness and 2 meters wide, and GFRP "I" shape profiles. To fix the GFRP profiles to the concrete deck, epoxy adhesive and metallic anchors (M10) were used. Several studies were performed, experimental and numerical, including creep effect, stress analyses, serviceability and ultimate limit analyses and cross-section optimization.

Creep tests carried out in the two prototypes of the bridge system, showed that using smaller distances between the M10 anchors does not bring any benefit to the bridge behavior, i.e., the long-term deflection of the prototypes was not affected by using a larger distance between the M10 anchors. Nonetheless, the deflection at 51 days of loading was increased $60 \%$ due to the creep effect, showing that this is an important phenomenon that should be taken into account in the bridge design. The stresses measured in the creep tests for both materials are far from their ultimate strength. This means that the bridge design is conditioned by service limit state due to the deflection.

The numerical simulations of the bridge revealed that to accomplish the deflection limit imposed by Eurocode 2, the geometry of the GFRP profile should be 550x200x15 mm $\mathrm{mm}^{3}$, maintaining the thickness of the SFRSCC deck constant and equal to $40 \mathrm{~mm}$. Furthermore, the results showed that the stresses in both materials are very similar to the stresses determined experimentally. However, using a 450x200x6.5 $\mathrm{mm}^{3}$ GFRP profile with a thin CFRP pre-stressed sheet of $0.50 \mathrm{~mm}$, the deflection limit was also accomplished.

From the numerical and experimental research, it was concluded that the connection between the deck and the profile can be made exclusively by epoxy adhesives, but the long term behavior of these adhesives when subjected to real weathering and to fatigue load conditions should be investigated, along with the dynamic response of the proposed concept.

\section{Acknowledgements}

This research is part of the research project QREN number 3456 - PONTALUMIS. The first and fourth Authors wish to acknowledge the research grants under this project. The authors also wish to acknowledge the Civitest Company, for the conception and development of the Steel Fiber Reinforced Self-Compacting Concrete used in this paper, and to Secil, ALTO, Clever Reinforcement (S\&P) and HILTI for the supplied materials and technical support.

\section{References}

ACI Committee 440., 1996. "State-of-the-Art Report on Fiber Reinforced Plastic Reinforcement for Concrete Structures", Manual of Concrete Practice, American concrete institute, Detroit.

Bakis, C. E., Bank, L. C., Brown, V. L., Cosenza, E., Davalos, J. F., Lesko, J. J., et al., 2002. "FiberReinforced Polymer Composites for Construction-State-of-the-Art Review", Journal of Composites for Construction, American Society of Civil Engineers, 73-87.

Bank, L. C., 2006. Composites For Construction: Structural Design with FRP Materials. Hoboken: John Wiley \& Sons. 
Basto, C.A.A.; Barros, J.A.O., 2008. "Numerical simulation of sections submitted to bending", Technical report 08-DEC/E-46, Dep. Civil Eng., School Eng. University of Minho, pp. 73.

Barros, J.A.O.; Pereira, E.B.; Santos, S.P.F., 2007. "Lightweight panels of steel fiber reinforced selfcompacting concrete", Journal of Materials in Civil Engineering, 19(4), 295-304.

CEB., 1993. CEB-FIP Model Code 1990. Lausanne: Thomas Telford Services.

CEN/CENELEC., 2003. "Eurocode 1: Actions on structures - Part 2: Traffic loads on bridges". Brussels: CEN.

CEN/TC250., 2002. "Eurocode - Basis of structural design". Brussels: CEN.

Chen, W. F., \& Lui, E. M., 2004. "Handbook of structural engineering" (Vol. 2nd ed.). Boca Raton: Taylor \& Francis Group.

Correia, J. P., 2004. "Glass fibre reinforced polymer (GFRP) pultruded profiles. Structural behaviour of GFRP-concrete hybrid beams". Master thesis, Instituto Superior Técnico, Lisbon. (in Portuguese)

Correia, J. P., 2008. "GFRP pultruded profiles in civil engineering: hybrid solutions, bonded connections and fire behaviour". PhD Thesis Instituto Superior Técnico, Lisbon.

CEN/TC250., 2004. "Eurocode 2: Design of concrete structures - Part 1-1: General rules and rules for buildings". Brussels: CEN.

Cunha, V.M.C.F. "Steel Fibre Reinforced Self-Compacting Concrete - from Micromechanics to Composite behaviour", PhD Thesis, University of Minho, Guimarães, Portugal, 2010.

EFCA., 2005. EFCA Aims. Retrieved February 19, 2010, from European Federation of Concrete Admixtures Associations: http://www.efca.info/publications.html

Gouveia, V. A., Barros, J., Azevedo, Á., \& Cruz, J. S. (2007). "Crack Constitutive Model to Simulate the Behavior of Fiber Reinforced Concrete Structures Failing in Punching". Porto: APMTAC.

Häßler, D., 2010. "Steel fibre reinforced self-compacting concrete thin layer for the flexural strengthening of ancient arch structures: experimental and numerical research". Master Thesis, University of Minho, Guimarães.

Keller, T., 2003. "Use of fibre reinforced polymers in bridge construction". International Association for Bridge and Structural Engineering, Zurich: IABSE-AIPC-IVBH.

Mendes, P. J., 2010. "Design and Analysis of a Pedestrian Bridge with GFRP Profiles and SFRSCC Deck". Master Thesis, University of Minho, Guimarães.

Monteiro, D. F., 2005. "Crack and creep behaviour of Polymer Concrete". PhD Thesis (in Portuguese), University of Porto, Porto.

Neto, A. B., \& Lebr, H., 2010. "Composite concrete/GFRP slabs for footbridge deck systems". Composite Structures, 2554-2564.

Ouchi, M., Nakamura, S.-a., Osterberg, T., Hallberg, S.-E., \& Lwin, M., 2003. "Applications of SelfCompacting Concrete in Japan, Europe and The United States". Federal Highway Administration, U.S. Department of Transportation.

Pereira, E.N.B., 2006. "Steel Fibre Reinforced Self-compacting Concrete: from material to mechanical behaviour", dissertation for Pedagogical and Scientific Aptitude Proofs, Department Civil Engineering, University of Minho, 188 pp, <http://www.civil.uminho.pt/composites >

Sena-Cruz, J.M.; Barros, J.A.O.; Azevedo, A.F.M.; Ventura-Gouveia, A., "Numerical simulation of the nonlinear behavior of RC beams strengthened with NSM CFRP strips", CMNE 2007 - Congress on Numerical Methods in Engineering and XXVIII CILAMCE - Iberian Latin American Congress on 
Computational Methods in Engineering, Abstract pp. 289, Paper n ${ }^{\circ} 485$ published in CD - FEUP, 20 pp., Porto, 13-15 June 2007.

Yu Bai, \& Keller, T., 2008. "Modal Parameter Identification for a GFRP Pedestrian Bridge". Composite Structures, 90-100. 


\section{List of Figures:}

Fig. 1 - Pedestrian bridge to be designed: a) Perspective view; b) Cross-section.

Fig. 2 - Cross-section of the tested prototypes.

Fig. 3 - Side view of the tested prototypes.

Fig. 4 - Configuration of the connection between the SFRSCC deck and the GFRP profiles.

Fig. 5 - Steps followed to assemble the connection.

Fig. 6 - a) Cement bag used to simulate the load; b) Load apparatus.

Fig. 7 - Position of the dial gauges in the prototype.

Fig. 8 -Time-deflection relationship of PROT_125 and PROT_200

Fig. 9 - Creep behavior: experimental and predicted numerical results.

Fig. 10 - Evolution of the flexural stiffness: experimental and predicted analytical results.

Fig. 11 - Time (days) versus strain: a) PROT_125 ; b) PROT_200.

Fig. 12 - Influence of creep in the strain profile after 21 days.

Fig. 13 - Influence of creep in the strain profile after 51 days.

Fig. 14 - SFRSCC constitutive model.

Fig. 15 - Moment-Curvature relationship for the analyzed cross-sections.

Fig. 16 - Mesh adopted in the FEM simulations.

Fig. 17 - Hybrid composite profile.

Fig. 18 - Girder's cost analysis.

Fig. 19 - Shear reinforcement apparatus. 


\section{List of Tables:}

Table 1 - SFRSCC mix proportion per $\mathrm{m}^{3}$.

Table 2 - Rheological and mechanical properties of the SFRSCC.

Table 3 - Strains measured and obtained analytically in both prototypes.

Table 4 - Stresses determined and obtained numerically for both prototypes [MPa]

Table 5 - Assumed values for the SFRSCC parametric study (see also Fig. 14).

Table 6 - Parametric study results for the SLS (maximum bending moment of $113.76 \mathrm{kN} . \mathrm{m}$ ).

Table 7 - Cross-sections of the FRP system in the FEM-based numerical simulations carried out.

Table 8 - Results for the serviceability limit states.

Table 9 - Results for the ultimate limit states.

Table 10 - Analyzed cross-sections.

Table 11 - Results for the serviceability limit states.

Table 12 - Results for the ultimate limit states.

Table 13 - Material/Elements cost. 


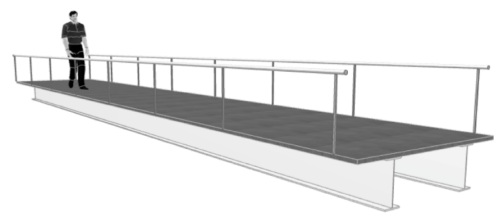

a)

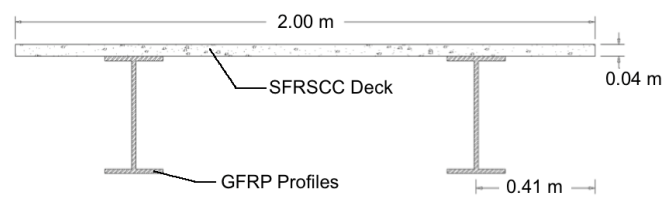

b)

Fig. 1 - Pedestrian bridge to be designed: a) Perspective view; b) Cross-section.

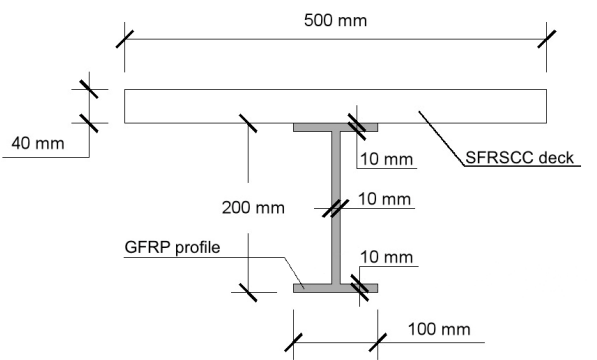

Fig. 2 -Cross-section of the tested prototypes.

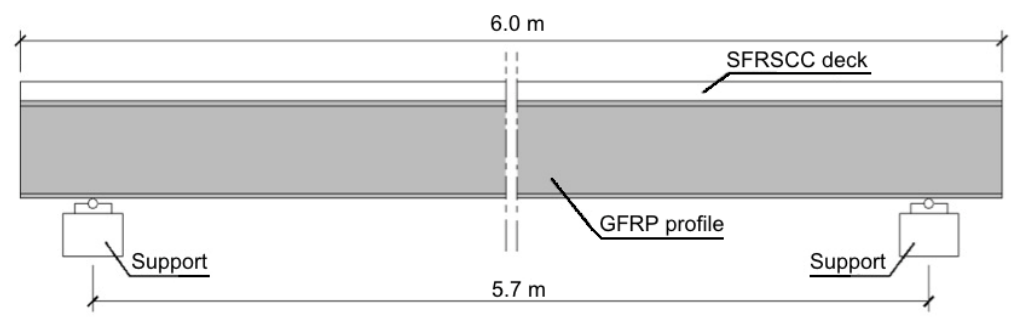

Fig. 3 - Side view of the tested prototypes.

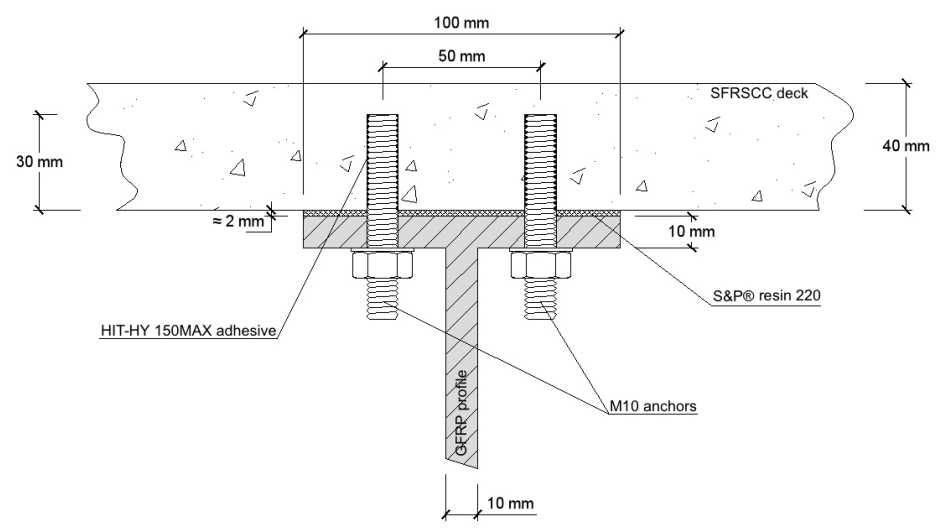

Fig. 4 - Configuration of the connection between the SFRSCC deck and the GFRP profiles. 


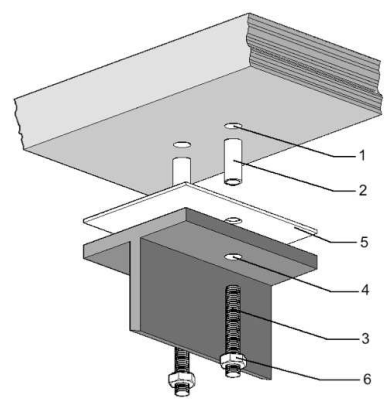

1- Drilling the holes in the SFRSCC deck

2-Applying the HIT-HY 150 MAX adhesive

3 - Bonding the $\mathrm{M} 10$ anchors

4 - Drilling the GFRP profiles

5 - Applying the S\&P resin 220

6 - Bolting the nuts

Fig. 5 - Steps followed to assemble the connection.

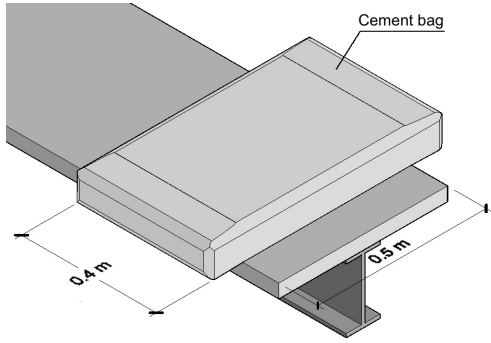

a)

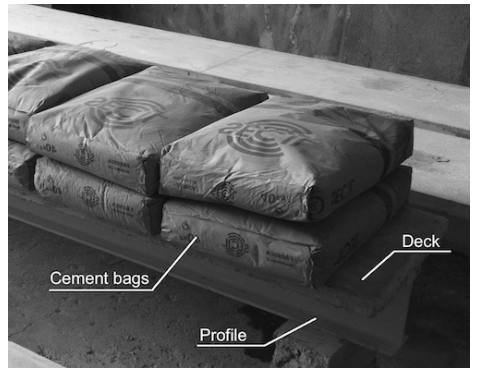

b)

Fig. 6-a) Cement bag used to simulate the load; b) Load apparatus.

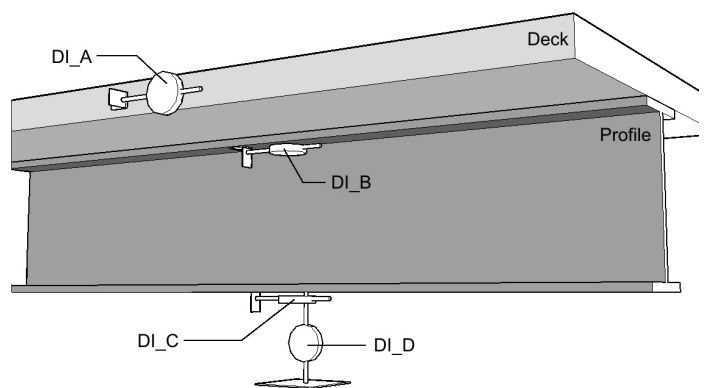

Fig. 7 - Position of the dial gauges in the prototype.

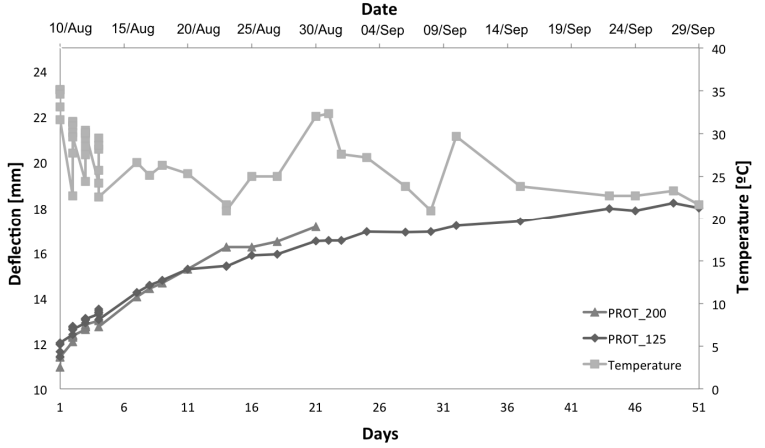

Fig. 8-Time-deflection relationship of PROT_125 and PROT_200. 


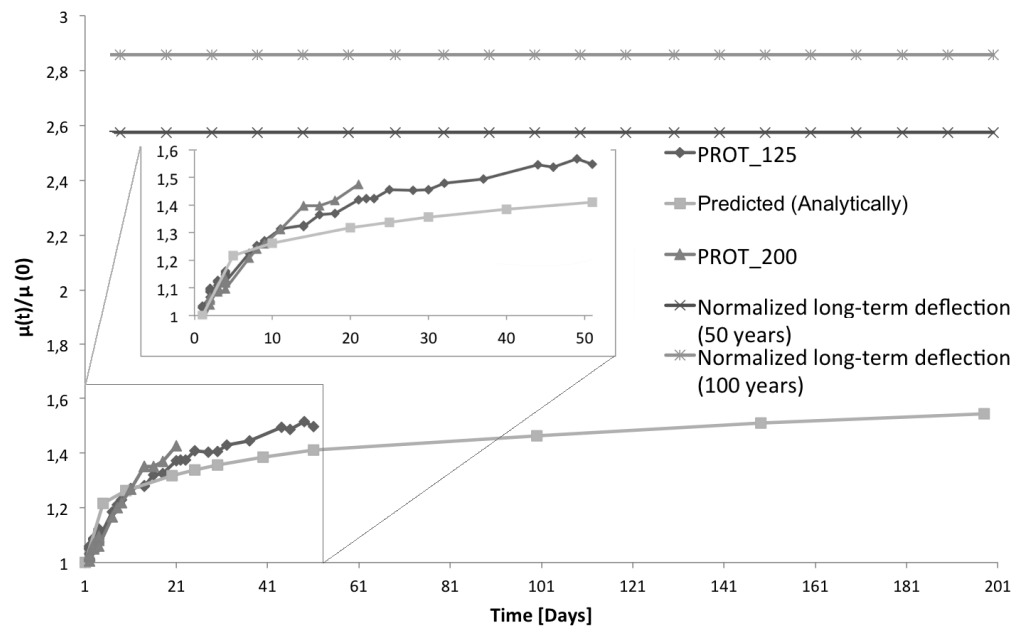

Fig. 9 - Creep behavior: experimental and predicted numerical results.

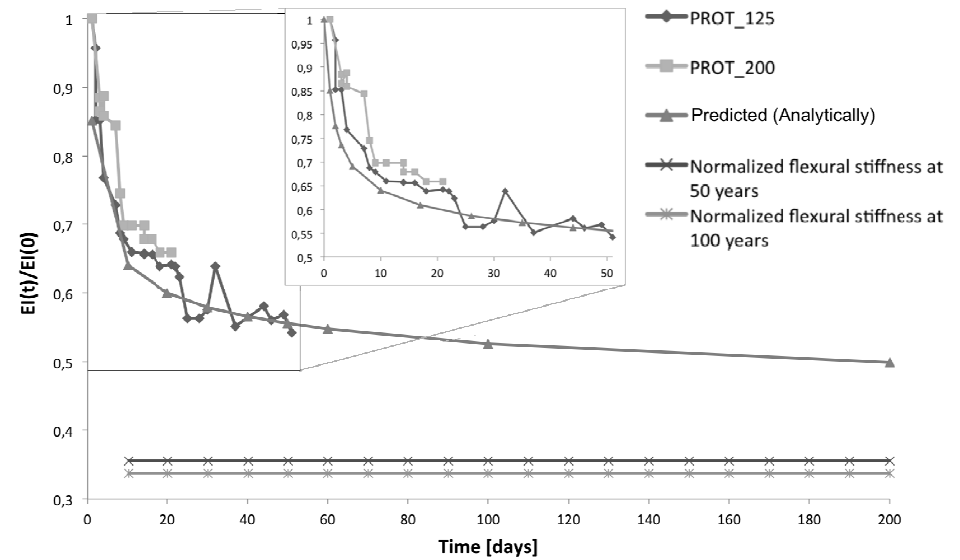

Fig. 10 - Evolution of the flexural stiffness: experimental and predicted analytical results.

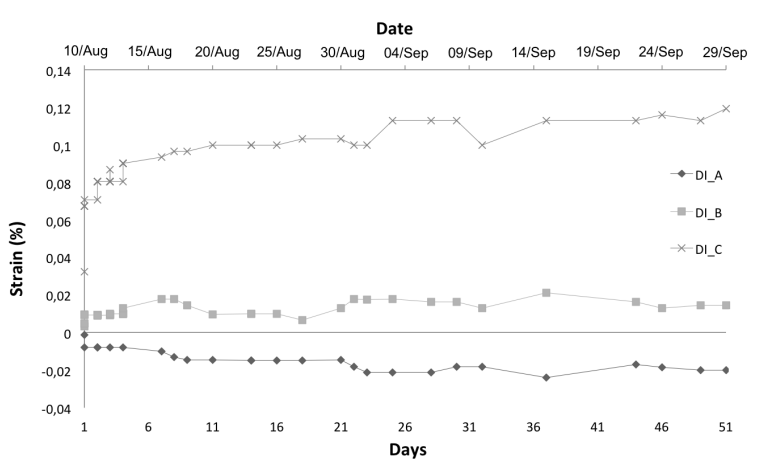

a)

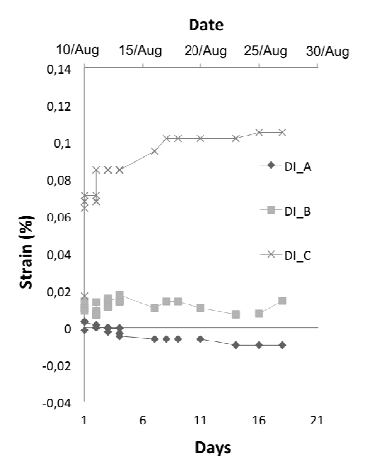

b)

Fig. 11 - Time (days) versus strain: a) PROT_125; b) PROT_200. 

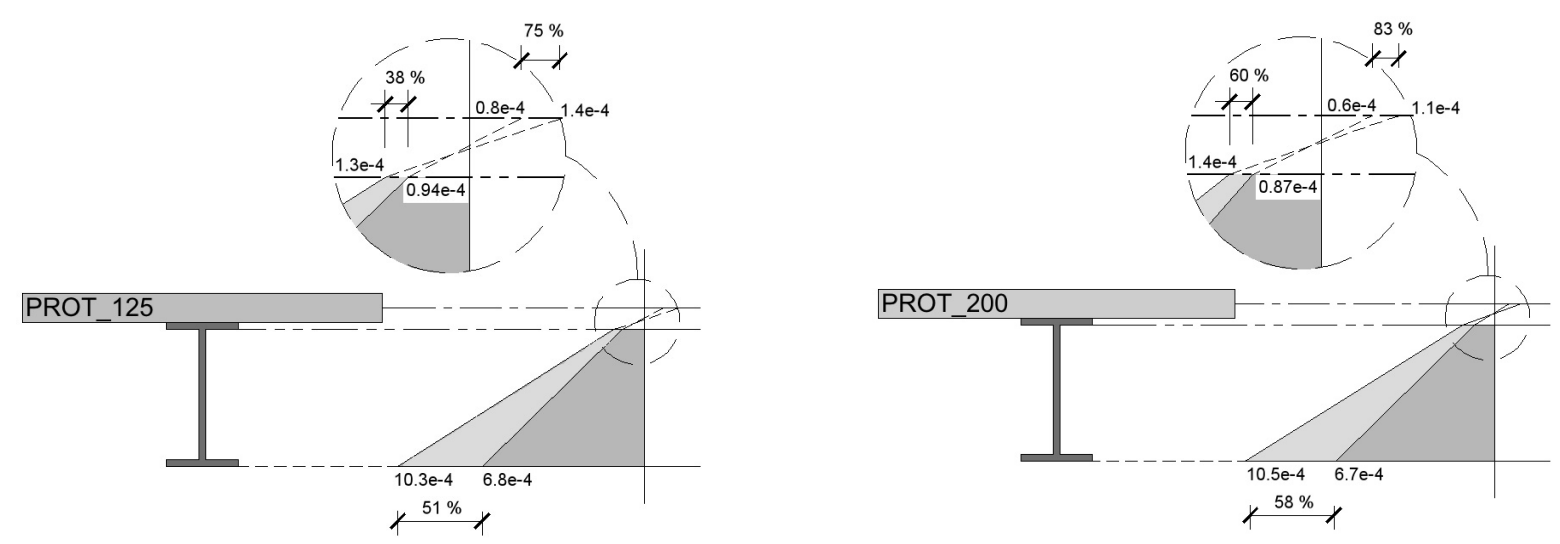

Fig. 12 - Influence of creep in the strain profile after 21 days.

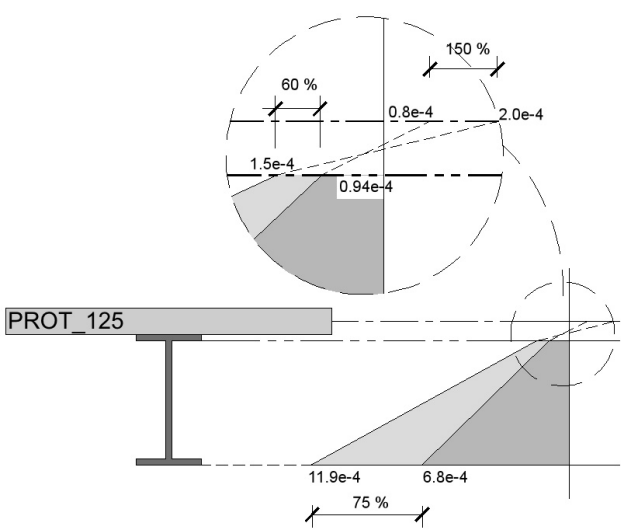

Fig. 13 - Influence of creep in the strain profile after 51 days.

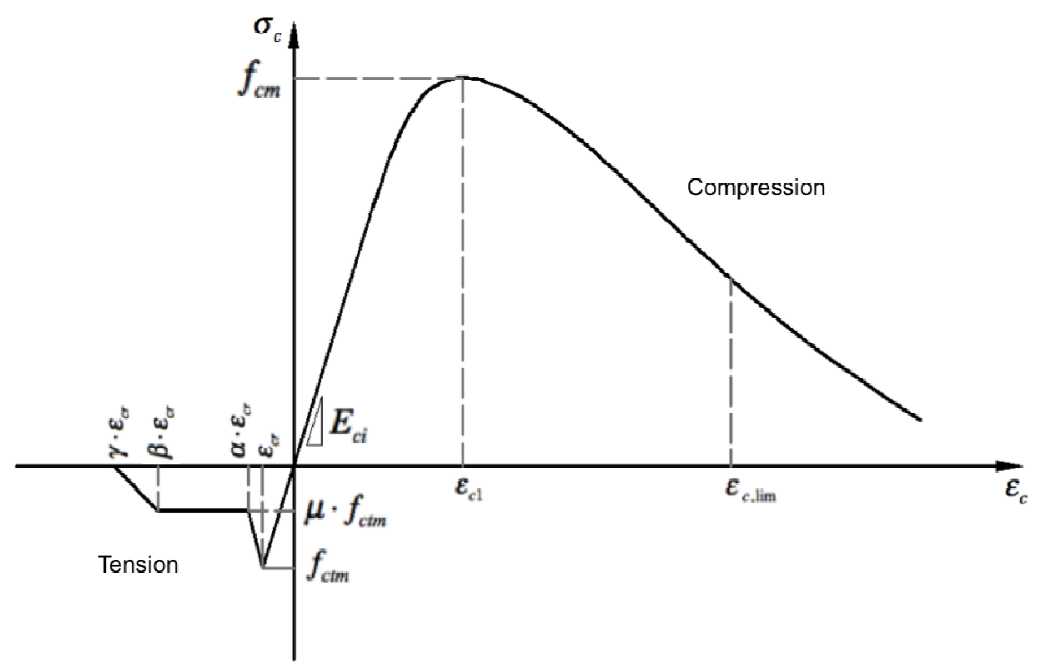

Fig. 14-SFRSCC constitutive model. 


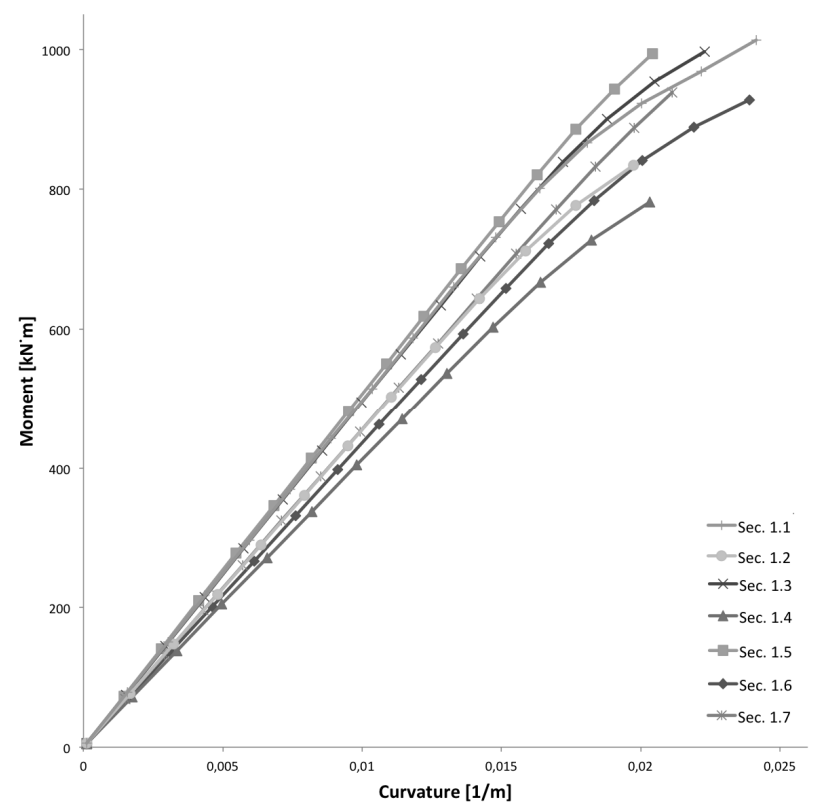

Fig. 15 - Moment-Curvature relationship for the analyzed cross-sections.

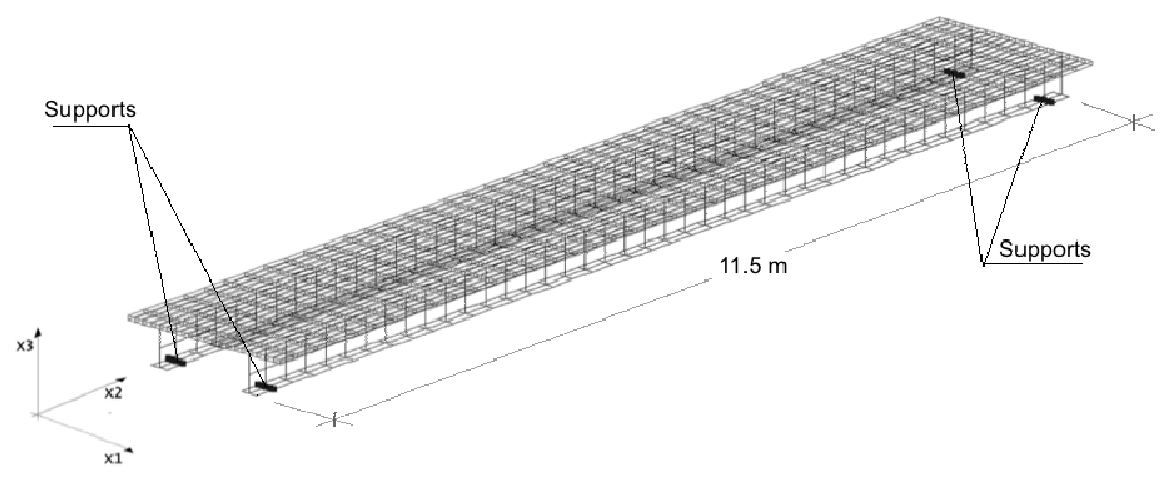

Fig. 16 - Mesh adopted in the FEM simulations.

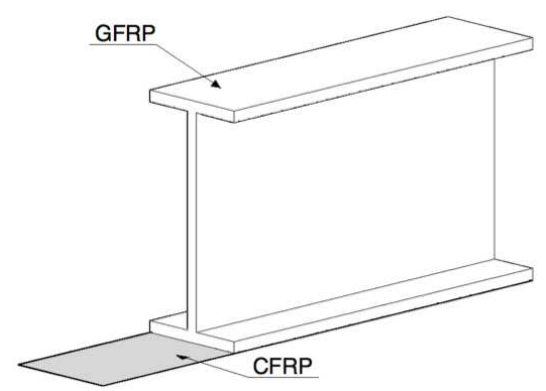

Fig. 17 - Hybrid composite profile. 


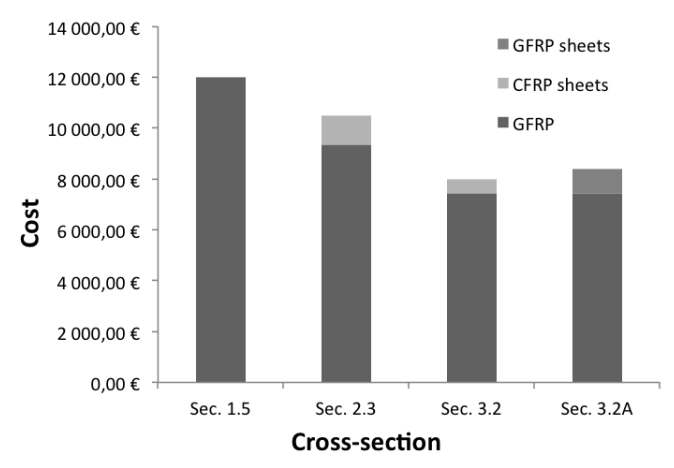

Fig. 18 -Girder's cost analysis.
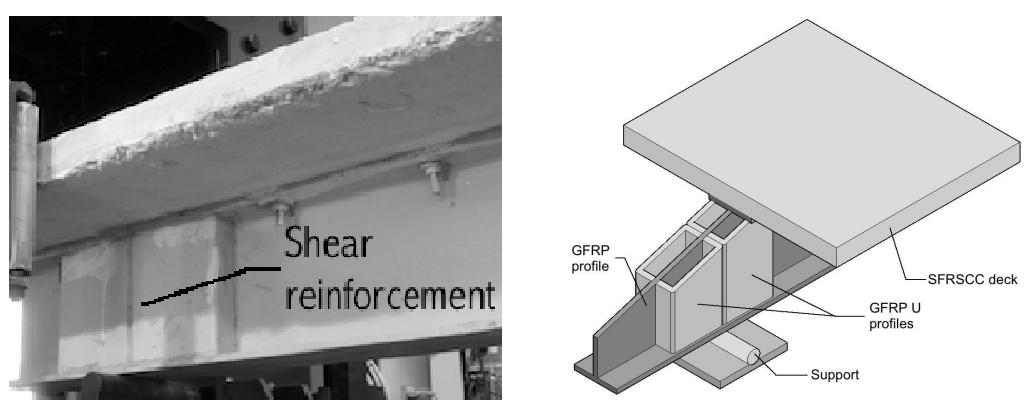

Fig. 19 - Shear reinforcement apparatus. 
Table 1 - SFRSCC mix proportion per $m^{3}$.

\begin{tabular}{cccccccc}
\hline $\begin{array}{c}\text { Cement } \\
{[\mathrm{kg}]}\end{array}$ & $\begin{array}{c}\text { Limestone filler } \\
{[\mathrm{kg}]}\end{array}$ & $\begin{array}{c}\text { Water } \\
{[\mathrm{kg}]}\end{array}$ & $\begin{array}{c}\text { Superplasticizer } \\
{[\mathrm{kg}]}\end{array}$ & $\begin{array}{c}\text { Fine sand } \\
{[\mathrm{kg}]}\end{array}$ & $\begin{array}{c}\text { River } \\
\text { sand }[\mathrm{kg}]\end{array}$ & $\begin{array}{c}\text { Crushed } \\
\text { stone } \\
{[\mathrm{kg}]}\end{array}$ & $\begin{array}{c}\text { Fibers } \\
{[\mathrm{kg}]}\end{array}$ \\
\hline 380.54 & 326.17 & 126.83 & 6.09 & 362.59 & 574.58 & 510.05 & 45.00 \\
\hline
\end{tabular}

Table 2-Rheological and mechanical properties of the SFRSCC.

\begin{tabular}{cc}
\hline Parameter & Value \\
\hline Slump flow & Diameter $=80 \mathrm{~cm}$ \\
& $\mathrm{~T} 50=4 \mathrm{~s}$ \\
V-funnel & $\mathrm{T}=9 \mathrm{~s}$ \\
L-box & $\mathrm{H} 2 / \mathrm{H} 1=0.8$ \\
Compressive strength & $59.87 \mathrm{MPa}$ \\
Tensile strength & $10.20 \mathrm{MPa}$ \\
Young's modulus & $32.00 \mathrm{GPa}$ \\
\hline
\end{tabular}

Table 3 - Strains measured and obtained analytically in both prototypes.

\begin{tabular}{|c|c|c|c|c|c|c|}
\hline \multirow{2}{*}{ Days } & \multicolumn{3}{|c|}{ PROT_125 } & \multicolumn{3}{|c|}{ PROT_200 } \\
\hline & DI_A & DI_B & DI_C & DI_A & DI_B & DI_C \\
\hline \multirow{2}{*}{1} & $-0.80 \mathrm{e}-4$ & $0.9 \mathrm{e}-4$ & $6.8 \mathrm{e}-4$ & $-0.6 \mathrm{e}-4$ & $0.9 \mathrm{e}-4$ & $6.7 \mathrm{e}-4$ \\
\hline & $(-1.11 \mathrm{e}-4)$ & $(0.52 \mathrm{e}-4)$ & $(8.01 \mathrm{e}-4)$ & $(-1.11 \mathrm{e}-4)$ & $(-0.52 \mathrm{e}-4)$ & $(8.01 \mathrm{e}-4)$ \\
\hline \multirow{2}{*}{21} & $-1.40 \mathrm{e}-4$ & $1.3 \mathrm{e}-4$ & 10.0e-4 & $-1.1 \mathrm{e}-4$ & $1.4 \mathrm{e}-4$ & $10.5 \mathrm{e}-4$ \\
\hline & $(-1.62 \mathrm{e}-4)$ & $(0.93 \mathrm{e}-4)$ & $(8.96 \mathrm{e}-4)$ & $(1.62 \mathrm{e}-4)$ & $(-0.93 \mathrm{e}-4)$ & $(8.96 \mathrm{e}-4)$ \\
\hline \multirow{2}{*}{51} & $-2.00 \mathrm{e}-4$ & $1.5 \mathrm{e}-4$ & $11.9 \mathrm{e}-4$ & $n /$ & & $n /$ \\
\hline & $(-1.86 \mathrm{e}-4)$ & $(1.13 \mathrm{e}-4)$ & $(9.45 \mathrm{e}-4)$ & $\mathrm{n} / \mathrm{a}$ & $\mathrm{n} / \mathrm{a}$ & $\mathrm{n} / \mathrm{a}$ \\
\hline \multirow{2}{*}{ Years } & \multicolumn{6}{|c|}{ In both Prototypes } \\
\hline & \multicolumn{2}{|c|}{ DI_A } & \multicolumn{2}{|c|}{ DI_B } & \multicolumn{2}{|c|}{ DI_C } \\
\hline 50 & \multicolumn{2}{|c|}{$(-2.82 \mathrm{e}-4)$} & \multicolumn{2}{|c|}{$(-1.47 \mathrm{e}-4)$} & \multicolumn{2}{|c|}{$(17.85 \mathrm{e}-4)$} \\
\hline 100 & \multicolumn{2}{|c|}{$(-2.86 \mathrm{e}-4)$} & \multicolumn{2}{|c|}{$(-1.35 \mathrm{e}-4)$} & \multicolumn{2}{|c|}{$(20.08 \mathrm{e}-4)$} \\
\hline
\end{tabular}

() values obtained analytically

Note: negative means compression 
Table 4 - Stresses determined and obtained analytically for both prototypes [MPa].

\begin{tabular}{|c|c|c|c|c|c|c|}
\hline \multirow{2}{*}{ Days } & \multicolumn{3}{|c|}{$\mathrm{PROT}_{-} 125$} & \multicolumn{3}{|c|}{$\mathrm{PROT}_{-} 200$} \\
\hline & $\mathrm{DI} A \mathrm{~A}$ & DI_B & DI_C & DI_A & DI_B & DI_C \\
\hline 1 & -2.36 & 1.66 & 25.41 & -1.26 & 2.85 & 21.25 \\
\hline \multirow{2}{*}{ Years } & \multicolumn{6}{|c|}{ In both prototypes } \\
\hline & \multicolumn{2}{|c|}{ DI_A } & \multicolumn{2}{|c|}{ DI_B } & \multicolumn{2}{|c|}{ DI_C } \\
\hline 50 & \multicolumn{2}{|c|}{-2.33} & \multicolumn{2}{|c|}{-2.14} & \multicolumn{2}{|c|}{25.63} \\
\hline 100 & \multicolumn{2}{|c|}{-2.35} & \multicolumn{2}{|c|}{-1.74} & \multicolumn{2}{|c|}{25.45} \\
\hline
\end{tabular}

Note: negative means compression

Table 5 - Assumed values for the SFRSCC parametric study (see also Fig. 14).

\begin{tabular}{lccc}
\hline \multicolumn{1}{c}{ Material Property } & Symbol & Unit & Value \\
\hline Initial Young's modulus & $E_{c i}$ & {$[\mathrm{MPa}]$} & 32000.00 \\
Strain at compressive & $\varepsilon_{c 1}$ & - & $2.3 \times 10^{-3}$ \\
strength & $f_{c m}$ & {$[\mathrm{MPa}]$} & 59.87 \\
Compressive strength & & & \\
Non-dimensional & $\varepsilon_{c, \text { lim }}\left(2 \times \varepsilon_{c 1}\right)$ & - & $4.6 \times 10^{-3}$ \\
critical strain on the & & & \\
compression envelope & $\varepsilon_{c r}$ & - & $1 \times 10^{-4}$ \\
Strain at tensile & $f_{c t m}$ & {$[\mathrm{MPa}]$} & 3.00 \\
strength & $\mu$ & - & 0.385 \\
Tensile strength & $\alpha$ & - & 1.03 \\
Tensile parameter 1 & $\beta$ & & 1646 \\
Tensile parameter 2 & $\gamma$ & - & 2470 \\
Tensile parameter 3 & $1.5 \gamma$ & & \\
Tensile parameter 4 & & & \\
& & & \\
\end{tabular}

Table 6 -Parametric study results for the SLS (maximum bending moment of $113.76 \mathrm{kN.m}$ ).

\begin{tabular}{|c|c|c|c|c|c|c|c|}
\hline $\begin{array}{l}\text { Sec. } \\
\mathrm{N}^{\circ}\end{array}$ & $\begin{array}{c}\text { Profile's } \\
\text { height } \\
{[\mathrm{mm}]}\end{array}$ & $\begin{array}{c}\text { Profile's } \\
\text { width } \\
\text { [mm] }\end{array}$ & $\begin{array}{c}\text { Thickness of } \\
\text { flange/web } \\
{[\mathrm{mm}]}\end{array}$ & $\begin{array}{c}\mathrm{EI} \\
{\left[\mathrm{kN} \cdot \mathrm{m}^{2}\right]}\end{array}$ & $\begin{array}{c}\text { Tensile } \\
\text { stress in } \\
\text { bottom } \\
\text { flange }\end{array}$ & $\begin{array}{c}\text { Concrete } \\
\text { compressive } \\
\text { stress } \\
{[\mathrm{MPa}]}\end{array}$ & $\begin{array}{c}\text { Instantaneous } \\
\text { Deflection } \\
{[\mathrm{mm}]}\end{array}$ \\
\hline & & & & & {$[\mathrm{MPa}]$} & & \\
\hline
\end{tabular}




\begin{tabular}{lllccccc}
\hline 1.1 & 600 & 250 & 10 & 49458 & 43.90 & 6.73 & 34.94 \\
1.2 & 600 & 250 & 9 & 45033 & 47.34 & 6.72 & 38.85 \\
1.3 & 580 & 200 & 12.5 & 48863 & 40.47 & 6.72 & 35.36 \\
1.4 & 580 & 200 & 10 & 41143 & 1.93 & 7.36 & 43.00 \\
1.5 & 550 & 200 & 15 & 50175 & 37.70 & 7.04 & 34.44 \\
1.6 & 550 & 200 & 12.5 & 43417 & 44.93 & 7.36 & 40.60 \\
1.7 & 500 & 250 & 15 & 45571 & 37.17 & 7.36 & 38.80 \\
\hline
\end{tabular}

Table 7-Cross-sections of the FRP system in the FEM-based numerical simulations carried out.

\begin{tabular}{ccccc}
\hline $\begin{array}{c}\text { Sec. } \\
\mathrm{N}^{\circ}\end{array}$ & $\begin{array}{c}\text { Profile height } \\
{[\mathrm{mm}]}\end{array}$ & $\begin{array}{c}\text { Profile width } \\
{[\mathrm{mm}]}\end{array}$ & $\begin{array}{c}\text { Thickness of } \\
\text { flange/web } \\
{[\mathrm{mm}]}\end{array}$ & $\begin{array}{c}\text { Thickness of } \\
\text { CFRP sheets } \\
{[\mathrm{mm}]}\end{array}$ \\
\hline 2.2 & 600 & 250 & 10 & 0.15 \\
2.1 & 550 & 200 & 15 & 0.15 \\
2.4 & 550 & 200 & 8 & 0.6 \\
2.5 & 550 & 200 & 10 & 0.1 \\
2.3 & 500 & 200 & 10 & 0.8 \\
2.7 & 500 & 250 & 10 & 0.4 \\
2.6 & 500 & 250 & 8 & 0.9 \\
\hline
\end{tabular}

Table 8 - Results for the serviceability limit states.

\begin{tabular}{|c|c|c|c|c|c|c|}
\hline $\begin{array}{c}\text { Sec. } \\
\mathrm{N}^{\circ}\end{array}$ & $\begin{array}{c}\text { SFRSCC } \\
\text { compressive } \\
\text { stress } \\
{[\mathrm{MPa}]}\end{array}$ & $\begin{array}{c}\text { GFRP } \\
\text { compressive } \\
\text { stress in top } \\
\text { flange } \\
\text { [MPa] }\end{array}$ & $\begin{array}{l}\text { GFRP tensile } \\
\text { stress in } \\
\text { bottom flange } \\
\quad[\mathrm{MPa}]\end{array}$ & $\begin{array}{l}\text { CFRP } \\
\text { tensile } \\
\text { stress } \\
{[\mathrm{MPa}]}\end{array}$ & $\begin{array}{c}\text { Instantaneous } \\
\text { deflection } \\
{[\mathrm{mm}]}\end{array}$ & $\begin{array}{c}\text { Long-term } \\
\text { deflection } \\
\text { (100 years) } \\
\text { [mm] }\end{array}$ \\
\hline 2.2 & 5.56 & 3.90 & 35.68 & 228.80 & 27.65 & 34.31 \\
\hline 2.1 & 5.88 & 4.52 & 31.73 & 202.20 & 27.00 & 33.92 \\
\hline 2.4 & 6.18 & 3.87 & 46.90 & 301.37 & 38.63 & 47.34 \\
\hline 2.5 & 6.28 & 4.13 & 46.01 & 294.75 & 37.70 & 46.51 \\
\hline 2.3 & 5.48 & 3.87 & 35.68 & 229.81 & 38.73 & 47.71 \\
\hline 2.7 & 6.50 & 4.38 & 41.59 & 266.30 & 38.05 & 47.05 \\
\hline
\end{tabular}




\begin{tabular}{|c|c|c|c|c|c|c|}
\hline 2.6 & 6.40 & 4.14 & 41.35 & 265.84 & 3.21 & 46.91 \\
\hline \multicolumn{7}{|c|}{ Table 9 -Results for the ultimate limit states. } \\
\hline & $\begin{array}{c}\text { Sec. } \\
\mathrm{N}^{\mathrm{o}}\end{array}$ & $\begin{array}{c}\text { SFRSCC } \\
\text { compressive } \\
\text { stress } \\
{[\mathrm{MPa}]}\end{array}$ & $\begin{array}{c}\text { GFRP } \\
\text { compressive } \\
\text { stress in top } \\
\text { flange } \\
{[\mathrm{MPa}]}\end{array}$ & $\begin{array}{l}\text { GFRP tensile } \\
\text { stress in } \\
\text { bottom flange } \\
{[\mathrm{MPa}]}\end{array}$ & $\begin{array}{l}\text { CFRP } \\
\text { tensile } \\
\text { stress } \\
{[\mathrm{MPa}]}\end{array}$ & \\
\hline & 2.2 & 8.06 & 5.85 & 52.42 & 336.57 & \\
\hline & 2.1 & 8.64 & 6.65 & 46.65 & 297.23 & \\
\hline & 2.4 & 9.10 & 5.70 & 69.07 & 443.68 & \\
\hline & 2.5 & 9.25 & 6.08 & 67.70 & 433.83 & \\
\hline & 2.3 & 9.65 & 6.42 & 62.47 & 400.12 & \\
\hline & 2.7 & 9.56 & 6.46 & 61.19 & 391.82 & \\
\hline & 2.6 & 9.41 & 6.10 & 60.88 & 390.85 & \\
\hline
\end{tabular}

Table 10 - Analyzed cross-sections.

\begin{tabular}{ccccc}
\hline $\begin{array}{c}\text { Sec. } \\
\mathrm{N}^{\mathrm{O}}\end{array}$ & $\begin{array}{c}\text { Profile height } \\
{[\mathrm{mm}]}\end{array}$ & $\begin{array}{c}\text { Profile width } \\
{[\mathrm{mm}]}\end{array}$ & $\begin{array}{c}\text { Thickness of } \\
\text { flange/web } \\
{[\mathrm{mm}]}\end{array}$ & $\begin{array}{c}\text { Thickness of } \\
\text { CFRP sheets } \\
{[\mathrm{mm}]}\end{array}$ \\
\hline 3.1 & 450 & 200 & 6.5 & 0.50 \\
3.2 & 450 & 200 & 8.0 & 0.40 \\
3.3 & 450 & 200 & 10 & 0.35 \\
3.4 & 450 & 200 & 12.5 & 0.25 \\
3.5 & 450 & 200 & 15 & 0.15 \\
\hline
\end{tabular}

Table 11 - Results for the serviceability limit states.

\begin{tabular}{|c|c|c|c|c|c|}
\hline $\begin{array}{c}\text { Sec. } \\
\mathrm{N}^{\circ}\end{array}$ & $\begin{array}{c}\text { SFRSCC } \\
\text { compressive } \\
\text { stress } \\
{[\mathrm{MPa}]}\end{array}$ & $\begin{array}{c}\text { GFRP } \\
\text { compressive } \\
\text { stress in top } \\
\text { flange } \\
{[\mathrm{MPa}]}\end{array}$ & $\begin{array}{c}\text { GFRP } \\
\text { tensile stress } \\
\text { in bottom } \\
\text { flange } \\
{[\mathrm{MPa}]}\end{array}$ & $\begin{array}{l}\text { CFRP } \\
\text { tensile } \\
\text { stress } \\
{[\mathrm{MPa}]}\end{array}$ & $\begin{array}{c}\text { Instantaneous } \\
\text { deflection } \\
{[\mathrm{mm}]}\end{array}$ \\
\hline 3.1 & 6.83 & 4.33 & 28.34 & 1400.36 & 35.70 \\
\hline 3.2 & 6.96 & 4.45 & 33.10 & 1430.54 & 38.50 \\
\hline 3.3 & 6.89 & 4.70 & 31.61 & 1420.61 & 36.14 \\
\hline 3.4 & 6.91 & 4.93 & 32.90 & 1428.21 & 36.06 \\
\hline 3.5 & 6.97 & 5.13 & 33.95 & 1434.39 & 36.05 \\
\hline
\end{tabular}


Table 12 - Results for the ultimate limit states.

\begin{tabular}{|c|c|c|c|c|}
\hline $\begin{array}{c}\text { Sec. } \\
N^{\circ}\end{array}$ & $\begin{array}{c}\text { SFRSCC } \\
\text { compressive } \\
\text { stress } \\
{[\mathrm{MPa}]}\end{array}$ & $\begin{array}{c}\text { GFRP } \\
\text { compressive } \\
\text { stress in top } \\
\text { flange } \\
\text { [MPa }]\end{array}$ & $\begin{array}{c}\text { GFRP } \\
\text { tensile stress } \\
\text { in bottom } \\
\text { flange } \\
\text { [MPa] }\end{array}$ & $\begin{array}{l}\text { CFRP } \\
\text { tensile } \\
\text { stress } \\
{[\mathrm{MPa}]}\end{array}$ \\
\hline 3.1 & 10.64 & 6.01 & 63.05 & 1623.65 \\
\hline 3.2 & 10.68 & 6.36 & 63.91 & 1627.87 \\
\hline 3.3 & 10.50 & 6.83 & 57.78 & 1587.70 \\
\hline 3.4 & 10.44 & 7.23 & 55.21 & 1570.26 \\
\hline 3.5 & 10.40 & 7.55 & 51.40 & 1558.25 \\
\hline
\end{tabular}

Table 13 - Material/Elements cost.

\begin{tabular}{lcc}
\hline \multicolumn{1}{c}{ Material/Element } & Unit & Cost $(€)$ \\
\hline S\&P C Sheet $240,200 \mathrm{~g} / \mathrm{m}^{2}$ & $€ / \mathrm{m}^{2}$ & 40,00 \\
S\&P C Sheet $240,300 \mathrm{~g} / \mathrm{m}^{2}$ & $€ / \mathrm{m}^{2}$ & 50,00 \\
S\&P C Sheet $240,400 \mathrm{~g} / \mathrm{m}^{2}$ & $€ / \mathrm{m}^{2}$ & 58,00 \\
S\&P G Sheet $90 / 10 \mathrm{AR}$ & $€ / \mathrm{m}^{2}$ & 25,00 \\
GFRP I-profile $550 \times 200 \times 15 \mathrm{~mm}^{3}$ & $€ / \mathrm{m}$ & 500,00 \\
GFRP I-profile $500 \times 200 \times 10 \mathrm{~mm}^{3}$ & $€ / \mathrm{m}$ & 390,00 \\
GFRP I-profile $450 \times 200 \times 8 \mathrm{~mm}^{3}$ & $€ / \mathrm{m}$ & 310,00 \\
\hline
\end{tabular}

